Full length article

\title{
Unified network analysis on the organization of an industrial metabolic system
}

\author{
Yupeng Fan ${ }^{\mathrm{a}}$, Qi Qiao ${ }^{\mathrm{a}, *}$, Weiping Chen $^{\mathrm{b}}$ \\ a Chinese Research Academy of Environmental Sciences, Beijing, 100012, China \\ ${ }^{\mathrm{b}}$ Research Center for Eco-Environmental Sciences, Chinese Academy of Sciences, Beijing, 100085, China
}

\section{A R T I C L E I N F O}

\section{Keywords:}

Industrial metabolic system

Social network analysis

Ecological network analysis

Network features

Network stability

Industrial park

\begin{abstract}
A B S T R A C T
Industrial parks have been playing a crucial role on driving regional economic development, but also been posing threats to local environment due to intensive resource consumption and waste emission. To analyze the trade-off between economic development and environmental pollution, we use an approach based on social and ecologic network analysis to survey the industrial metabolic network and explore their functional characteristics. We conduct a case study in Hefei economic and technological development area, whose components (environment/industrial sectors) are treated as nodes and the relationships (material/energy flows) between nodes are seen as links in this network. Results show that the relationships distribution between components in the entire network basically shows a feature of decentralization. Environment controls the relationships in the network with the greatest advantage. Other industry and fast moving consumer goods industry have considerable ability to build relationships with other components, and are very important for constructing the network. The whole network shows mutualism and synergism based on the ecological relationships between components. In addition the park had a network stability of 0.70 , indicating it was in an evolutionary phase, and most material/energy flows are used to improve operational efficiency rather than maintain network stability. This study could provide scientific basis for optimizing industrial park management, thereby reducing environmental pollution and promoting resources conservation.
\end{abstract}

\section{Introduction}

Enterprises cannot develop individually. They created various relations based on resource supply, market trade or social connection, and thus formed the industrial systems with the network structure, among which industrial parks are common examples. In the past 30 years, China established more than 2000 industrial parks, which accounted for $>60 \%$ of gross national industrial output value and $>$ $50 \%$ of GDP (Bao, 2013). In 2014, the GDP growth rate of industrial parks, $29.1 \%$, prominently exceeded that of the national average, $7.4 \%$ (CADZ, 2014). Meanwhile, various environmental issues brought by industrial parks have come to the fore (Yune et al., 2016; Liu et al., 2016). It is therefore urgent that industrial metabolic system should be studied deeply and systematically in order to solve the serious industrial pollution and relieve conflicts between regional economic development and resources supply.

In the last 20 years researchers have started considering economic systems as network structures, where independent entities interact with each other (Low, 1997; Håkansson, 1997; Nasini et al., 2015). Accord- ing to the classical definition, the industrial system can be defined as a network where sectors represent the nodes and the inter-sectoral relationship are the edges (Håkansson,1997). As a social-ecological system, the industrial system has both social and natural attributes. Material and energy flows are fundamental to the discussion of environmental issues in industrial systems (Andersen et al., 2007; Nandy et al., 2015). We can examine the network characteristics using methods from both social network analysis (SNA) and ecological network analysis (ENA).

SNA is a collection of theories and methods that assumes that the behavior of actors (individuals, groups, organizations, etc.) is profoundly affected by their ties to others and the networks in which they are embedded (Furht, 2010). SNA provides both a visual and a mathematical analysis of social relationships (Scott, 2012). Most studies about SNA have been conducted to investigate research relationships and trends (Ghafouri et al., 2014; Patterson et al., 2013), interorganizational collaborations in the study of mental health systems (Provan and Milward, 1995), tourism research (Erkus-Ozturk and Eraydin, 2010; Scott et al., 2011), sport research (Quatman and

\footnotetext{
* Corresponding author.

E-mail addresses: 531631392@qq.com, qiaoqi@craes.org.cn (Q. Qiao).
} 
Chelladurai, 2008; Love and Andrew, 2012), construction project management research (Chinowsky and Taylor, 2012), and industrial ecology research (Kim and Perez, 2015).

Similarly, ENA provides methods for analyzing the interactions between ecosystem's structures and functions, revealing the integrity and complexity of ecosystem behaviors (Jørgensen and Fath, 2006; Fath, 2007). ENA can identify and quantify the direct and indirect interactions within a system, which determines the system's overall status of operation (Patten and Higashi, 1995; Fath and Patten, 1999a,b). It therefore can be used to quantify the path structure of a system (Fath and Patten, 1999a,b; Borrett and Patten, 2003; Fath, 2007), the patterns of the ecological flows (Finn, 1976; Fath and Patten, 1999a,b), and the relationships between the components of the system (Ulanowicz, 2004; Fath, 2007). ENA has been widely applied to study natural ecosystems (Baird et al., 2008; Schaubroeck et al., 2012; Small et al., 2014), and its applications in the metabolism of artificial systems have recently become popular (Zhang and Wang, 2006; Yang et al., 2012), but there are only very few such studies for industrial metabolism in Chinese industrial systems.

There are some studies using SNA to analyze networks for industrial symbiosis systems (Schiller et al., 2014; Zhang et al., 2013; Zhang et al., 2016). In this paper, we performed a study combining SNA and ENA to explore a deep insight into the whole industrial metabolic system, not only the industrial symbiosis system. We try to answer one scientific question: Will the energy and material flows lead to more or less harmonious relationships between the diverse components of the industrial system? The aim of combining SNA and ENA methods in our study is to better understand complex systems of material or energy flows in industrial systems. We attempt to integrate the unified network theory with information about resource flows to understand operation patterns and stability in industrial system networks. Based on this model, we examined the functional and structural traits of the system to provide a theoretical and practical basis for optimizing and managing industrial metabolism of industrial parks. We conducted a case study of Hefei economic and technological development area (HFETA) to display how this model can be used. Section 2 details the method of social network analysis and ecological network analysis, and describes the industrial metabolic network in a typical industrial park-Hefei economic and technological development area. Section 3 presents the results of this case study, including the nodes centralities, the ecological relationships between nodes, and the stability of the network. A discussion of the results is in Section 4, and a main summary of our study is in Section 5 .

\section{Methodology}

\subsection{Network modelling of industrial metabolism}

In this study we construct a network to describe the industrial metabolism of industrial park. A network is a structure amounting to a set of objects in which some pairs of the objects are in some sense "related". The objects correspond to mathematical abstractions called vertices (also called nodes or points) and each of the related pairs of vertices is called an edge (also called an arc or line) (Balakrishnan, 1997). A industrial metabolic network consists of a set of nodes (industrial and other sectors, defined as $\mathrm{n}_{1}, \mathrm{n}_{2}, \ldots .$. ), and links (material/energy flows, defined as $1_{1}, 1_{2}, \ldots .$. ) between nodes. The industrial metabolic system could be portrayed by mimicking natural ecosystems. Firstly, energy and raw materials suppliers such as power plant play the role of producers, secondly, industrial enterprises are the consumers consuming energy and materials, and thirdly the industrial wastes including solid wastes and wastewater enter the decomposers, such as, wastewater treatment plant, or solid waste disposal department. Moreover the waste/byproduct exchanges between industrial sectors are taken into account. The ecological flows between components are divided into several parts: the energy provided from environment to industrial enterprises for industrial production, such as coal, gasoline, diesel fuel, natural gas, electricity; raw materials input, including steel and iron, copper, aluminum, glass, rubber and plastic, etc.; waste/byproducts and residue heat generated from one component are delivered to other components; solid waste and wastewater flow into the waste treatment facilities; and the products flow into the ambient environment. For the convenience of analysis, the material and energy flows in the industrial metabolic system should be converted into a unified unit of measurement-emergy, based on the corresponding transformities (Odum, 1988, 1996; Odum et al., 2000; Brown and Bardi, 2001).

\subsection{Social network analysis}

SNA, a method that involves descriptive and structure-based analysis, is akin to structural analysis (Scott, 2012). It is significant if one wants to understand the structure of the network in order to obtain insights about how the network "works" and make decisions upon it by either inspecting characteristics of node/link (e.g. centrality) or by investigating metrics at the whole network cohesion (e.g. density) (Sapountzi and Psannis, 2016; Vicari et al., 2014). Seeking to disclose the effects that structural features may have on the actors, socialnetwork analysis uses some metrics, which will be briefly introduced below (Borgatti et al., 2002).

Three actor-level network measures are used to survey key nodes in the network: degree centrality, betweenness centrality and closeness centrality. Degree centrality gauges how connected a node is within a network and is simply measured by counting the number of direct connections each node has with other nodes in the network (Freeman, 1997). An actor with a high degree centrality in the network can communicate directly with many other actors and is highly apparent and prominent (Wasserman and Faust, 1994). Betweenness centrality surveys the number of times that an actor is on the shortest path between other pairs of actors (Freeman, 1997). Hence it symbolizes the ability of some nodes to control (or "broker") the flow of connectivity (information, resources etc.) within the network; or to connect other disconnected nodes. Closeness centrality stresses the distance of a node to all others in the network. The geodesic distance, between pairs of nodes, is the most usually used measure of closeness, which calculates the distance from a node to the others and reflects the availability, health and security of nodes. In network analysis, a node has high closeness centrality if it is connected to the others directly or through a few intermediaries. Nodes with high closeness probably receive resources faster than the others since fewer intermediaries exist among them.

With the help of specialized SNA software packages, social networks has been able to comprehend and depict a broad range of network characteristics. In our study, we use UCINET 6, a procedure developed by Borgatti and his colleagues for the social sciences (Borgatti et al., 2002), to analyze the above metrics. UCINET 6 was picked out from a series of available instruments due to its relative ease-of-use and a wide range of analysis options (Huisman and Van Duijn, 2005). NetDraw software was applied to draw the relationships among the nodes in the network (Borgatti 2002). NetDraw's multidimensional scaling algorithms were used to place actors according to the similarity in their geodesic distances (shortest path lengths) to other actors (Hanneman and Riddle 2005).

\subsection{Ecological network analysis}

\subsubsection{Network utility analysis (NUA)}

NUA is applied to assess the mutual relationships between nodes in the industrial metabolic network. The mutual benefit between nodes is assessed through a matrix of mutualism (Fath and Borrett, 2006; Fath, 2007). The direct relationship between components was appraised by a direct utility matrix $\mathrm{D}$, whose element $d_{i j}$ is defined as 
$d_{i j}=\frac{f_{i j}-f_{j i}}{\sum_{j=1}^{n} f_{i j}}$

Where $f_{i j}$ is the flow from node $j$ to node $i$, in a network with n nodes. $d_{i j}$ represents the utility of the flow $f_{i j}$ (Fath, 2012; Ahuja et al., 1988).

The integral relationship should be evaluated by considering both direct and indirect effects in the system, thus it can be expressed using the integral utility matrix $\mathrm{U}$ :

$U=D^{0}+D^{1}+D^{2}+D^{3}+\cdots+D^{l}+\cdots$

Where $D^{0}=I, I$ is the identity matrix, $D^{0}$ represents the self-feedback of flows through each node, $D^{1}$ shows the utility of the direct flows between any two nodes in the network along a path of length 1 , and $D^{l}$ $(l>1)$ represents the indirect flow utility along paths of $l$ steps. Element $u_{i j}$ represents the dimensionless integral value of $d_{i j}$ and $U$ depicts the integral utility matrix. Using a Leontief inverse matrix, $U$ can be calculated as follows (Fath and Patten, 1999a,b):

$U=\sum_{l=0}^{\infty} D^{l}=(I-D)^{-1}$

The positive and negative signs of the elements in $U$ define the pattern of the relationship between two components. $(+,+)$ stands for a mutualistic relationship, $(+,-)$ for an exploitative relationship, $(-$, $+)$ for an exploited relationship, $(-,-)$ for a competitive relationship and $(0,0)$ for a neutralism relationship (Fath, 2007). In this paper, mutualism index $(\mathrm{M})$ and synergism index $(\mathrm{S})$ were introduced for the industrial metabolic system to reflect the proportion of positive signs to negative signs and the total magnitude of elements (Fath, 2007; Fath and Patten, 1998). They can be expressed as follows:

$M=U_{+} / U_{-}$

$S=\sum_{j=1}^{n} \sum_{i=1}^{n} u_{i j}$

Where $U_{+}$and $U_{-}$are the number of positive signs and negative signs in matrix $U$, respectively. If $M>1$, the industrial system presents mutualism overall(Fath, 2007). While $S>0$, synergism occurs in the system from the whole perspective(Fath and Patten, 1998).

\subsubsection{Efficient and stability for network organization}

Resilience is a key system feature that has been depicted in many ways, for example, as the ability of a system to absorb shocks, to be flexible when facing with disturbances, and to be able to reorganize to new stable states after disruptions. Meanwhile efficiency is another important aspect which needs consideration in analyzing stability, since pursuing the efficiency which ensures higher benefits with lower costs is the core interests of enterprises in the industrial park. Consequently, this study investigates the resilience and efficiency of the industrial system based on the information entropy theory. Using the Shannon Diversity Index (Shannon and Weaver, 1948; Molles and Cahill, 1999), the information measure of the flows in network system can be calculated:

$H=-\sum_{i j} \frac{f_{i j}}{T} \log \left(\frac{f_{i j}}{T}\right)$

where $T$ is the total system throughflow that is the sum of all the flows in the network. Assuming each pair of components has an equal flow, the largest theoretical connecting diversity $H_{\max }$ can be calculated as follows:

$H_{\max }=-\log \frac{1}{n(n-1)}$

where $\mathrm{n}$ is the number of components in the system. $H / H_{\max }$, which represents the ecological connection degree of the system, reflects the efficiency for transferring flows between components. While $1-H / H_{\max }$ shows the resilience of the network, thereby the network stability (NS) can be defined:
$N S=\frac{1-H / H_{\max }}{H / H_{\max }}$

When NS $=1$, the network achieves the most stable state; NS $<1$ shows the system is in the evolutionary phase, most flows contribute to the efficiency; when NS $>1$, the system has developed to a mature phase, indicating more flows are distributed to maintain the structure stability of the system rather than improve efficiency.

The system's capacity consists of ascendency and redundancy, which are mutual counterparts. ENA can demonstrate a system's ascendency and redundancy (Ulanowicz et al., 2009; Ulanowicz, 2011). The ascendency shows how well organized these material and energy flows are. The redundancy exhibits redundant links of a system to endure disturbances. The indicator of robustness is applied to recognize the balance between the system's ascendency and redundancy, which is fundamental for a system's vitality. They can be calculated as follows (Ulanowicz et al., 2009; Ulanowicz, 2011).

$A=\sum_{i j} f_{i j} \log \left(\frac{f_{i j} T}{T_{i} \cdot T_{j}}\right)$

$\theta=-\sum_{i j} f_{i j} \log \left(\frac{f_{i j}^{2}}{T_{i} T_{j}}\right)$

$C=A+\theta$

$R=-\left(\frac{A}{C}\right) \log \left(\frac{A}{C}\right)$

Where $T_{i}$. is the sum of all the flows from other nodes to node $i$; $C$ is system capacity, which represents the scaled indeterminacy in aggregate system level; A is the system ascendency, which describes the scaled average mutual constraint of the system, and $\theta$ represents the system redundancy, which shows the scaled conditional entropy (Ulanowicz, 2001); R represents robustness. Eq. (11) shows that the capacity for a system to undergo evolution or self-organization consists of two aspects: It must be capable of exercising adequate directed power (ascendency) to maintain its integrity over time; meanwhile, it must sustain a store of flexible actions (redundancy) that can be used to cope with the stress of disturbances.

\subsection{Data}

HFETA was chosen for case study. The park description is in supplementary material. We collected 150 questionnaires from the enterprises to obtain data about materials use and energy consumption. Meanwhile we extracted pertinent information, including the industrial sectors, economic and social development, waste/byproduct exchange, product and waste, from local statistical yearbook, government documents, and environmental reports. We also conduct key-informant interviews for data valid confirmation and holistic observation. The year of 2014 is chosen as the base year.

The industrial metabolic system could be divided into 8 individual components by analogy with natural ecosystems and based on their properties in this study park. Firstly, energy and raw materials providers such as environment and power plant play the role of producers, secondly, industrial sectors (automobile manufacturing industry, equipment manufacturing industry, household appliances industry, fast moving consumer goods industry, and other industry) are the consumers consuming energy and materials, and thirdly the industrial wastes including solid wastes and wastewater enter the decomposers, i.e., waste treatment sector. We use emergy method to quantify the flows between components (Odum, 1996; Odum et al., 2000; Brown and Bardi, 2001). Emergy is delineated as the sum of all inputs of available energy directly or indirectly needed by a process to provide a given product when the inputs are conveyed in the same form of energy, usually solar energy (Odum, 1996).The various ecological flows are difficult to be unified. Emery can address this dilemma since it 
can incorporate various types of flows (material and energy flows) interacting in industrial system in a common unit: the solar emjoule (sej). Eco-flows are converted from their native units (e.g., $\mathrm{J}$ of energy, $\mathrm{t}$ of mass) into sej using a conversion factor called "transformity", which is the emergy required to make a unit of one certain energy or a given product(Odum, 1996; Odum et al., 2000; Brown and Bardi, 2001). Table 1 (Appendix) summarizes the emergy-based flows $\left(f_{i j}\right)$ for all of the inputs and outputs of each component at HFETA. The flows mainly are divided into 4 categories. Firstly, the most important flows are raw materials and energy supplied from the environment to all sectors $\left(3.97 \mathrm{E}+21\right.$ sej), including $f_{21}, f_{31}, f_{41}, f_{51}, f_{61}, f_{71}, f_{81}$; secondly, the waste/by-products are exchanged (including energy cascade) between components $(1.17 \mathrm{E}+20 \mathrm{sej})$, which is the core for eco-industrial development to reduce resources consumption and environmental pollution, including $f_{32}, f_{42}, f_{52}, f_{62}, f_{72}, f_{73}, f_{74}, f_{75}, f_{46}, f_{76}, f_{57}, f_{67}$, $f_{78}$; thirdly, the waste generated from industrial sectors to waste treatment sector $\left(f_{82}, f_{83}, f_{84}, f_{85}, f_{86}, f_{87}\right)$ is an important portion to alleviate the environmental burden $(2.48 \mathrm{E}+19 \mathrm{sej})$. Finally, the products and some wastes from industrial sectors to environment need to be taken into account in this study, such as $f_{12}, f_{13}, f_{14}, f_{15}, f_{16}, f_{17} . f_{18}$. The last category of flows achieves $3.13 \mathrm{E}+21$ sej.

\section{Results}

\subsection{Social network analysis}

We use netdraw to graph the industrial system network at HFETA (Fig. 1, Supplementary material). Nodes were placed according to the similarity in their geodesic distances to other actors. Flows between nodes were described in supplementary material. As shown in Fig. 1, environment and thermal power plant are located in the center of the network, other industry and waste treatment sector are located closer to the center, and automobile manufacturing industry, equipment manufacturing industry, household appliances industry and fast moving consumer goods industry are further away from the center.

The density of this network (the relative number of edges) is 0.5714 , signifying the ties have actually occupied over the half of the possible ties the network has. The high density in the network shows the dense connections between the components in the network.

The degree centrality of components in this network is shown in Table 1. Environment, thermal power plant, other industry, and waste treatment sector have the same degree of 7 , which are the most active actors, followed by fast moving consumer goods industry and equip- ment manufacturing industry, which are located in the moderately prominent relationship positions. Automobile manufacturing and household appliances industry have the smallest degree of 4, indicating weaker relationships in the network.

The betweenness of all nodes are also listed in Table 1. Environment has the largest betweenness of 18.500, indicating it is located in the center of the network, controlling the connectivity with the greatest advantage. Other industry and fast moving consumer goods industry have bigger betweenness centrality, meaning they have considerable ability to connect to other components, which is very important to construct the network. Other nodes were placed in the periphery of the network. The network centralization index equals $42.18 \%$, indicating that relationships basically shows a decentralized distribution feature, that is, the entire network does not depend on one point to a large extent.

The closeness centrality is the sum of the distance (by various approaches) from each ego to all others in the network. It is calculated based on geodesic distance in this study. The actor which has the largest farness is weakest in power, resources, influence and prestige. Automobile manufacturing and household appliances industry were placed in the periphery; environment, thermal power plant, other industry, waste treatment sector were located relatively in the central place in the network. Equipment manufacturing industry and fast moving consumer goods industry were located neither in the center nor in the periphery.

\subsection{Ecological network analysis}

\subsubsection{Total ecological relationships}

The direct utility intensity matrix (D) and the integral utility intensity matrix (U) for HFETA were calculated according to Eqs. (1) and (3) (Supplementary material, Tables S1 and S2), and then the mutual relationships between nodes were determined. The integral utility consists of direct and indirect utility. By comparing the direct and integral utility for each node, we can determine the relative effect of the indirect flows. None of the elements in the integral utility are 0 (Supplementary material, Table S2), while in Table S1, there are 20 elements (31.25\% of the total 64 elements) having no direct utility and their integral utilities presented in Table S2 depend on indirect utilities. A quantity of the ultimate relationships among components of the network are determined by indirect flows, since much utility mainly consists of indirect utility that is contributed by indirect flows passing through an intermediate node.

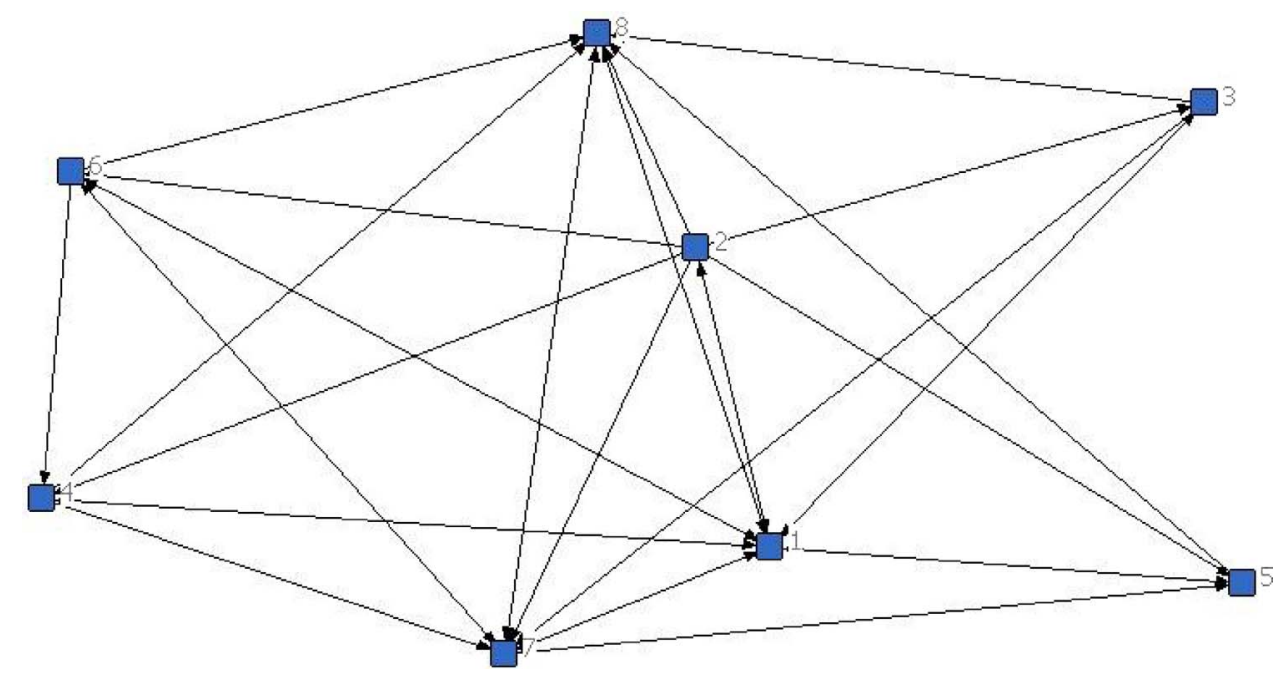

Fig. 1. Industrial system network at HFETA.

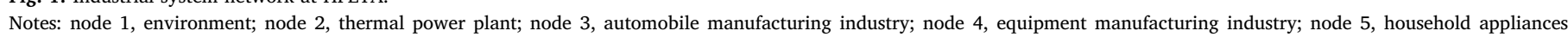
industry; node 6, fast moving consumer goods industry; node 7, other Industry; node 8, waste treatment sector; 
Table 1

The centrality metrics of all eight components in the network by degree, betweeness and closeness.

\begin{tabular}{|c|c|c|c|c|c|c|}
\hline component & Degree & nDegree & Betweenness & nBetweenness & Closeness & nCloseness \\
\hline 1 & 7.000 & 100 & 18.500 & 44.048 & 0.143 & 100.000 \\
\hline 2 & 7.000 & 100 & 0.167 & 0.397 & 0.143 & 100.000 \\
\hline 3 & 4.000 & 57.143 & 0.167 & 0.397 & 0.100 & 70.000 \\
\hline 4 & 5.000 & 71.429 & 0.167 & 0.397 & 0.111 & 77.778 \\
\hline 5 & 4.000 & 57.143 & 0.167 & 0.397 & 0.100 & 70.000 \\
\hline 6 & 5.000 & 71.429 & 0.667 & 1.587 & 0.111 & 77.778 \\
\hline 7 & 7.000 & 100.000 & 4.167 & 9.921 & 0.143 & 100.000 \\
\hline 8 & 7.000 & 100.000 & 0.167 & 0.397 & 0.143 & 100.000 \\
\hline
\end{tabular}

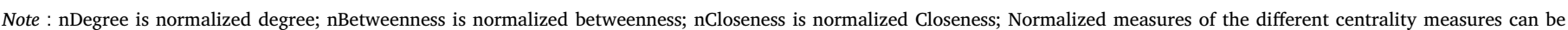
compared with each other.

The ecological relationships among the nodes can be determined based on the utility matrix. In $\mathrm{U}$, there are 28 pairs of ecological relationships, excluding diagonal elements, of which 9 pairs represent mutualism and 6 pairs present competition, accounting for $32.1 \%$ and $21.4 \%$ of the total number, respectively. Exploitation and exploited relationships account for the remaining 13 pairs of relationships (46.4\% of the total), which occupy the main relationships in the system.

$M$ equals 1.56 based on Eq. (4). Since $M>1$, the positive signs dominate the matric and the system is mutualistic regarding the overall performance. The positive self-feedbacks of the components also have a contribution. There are equal numbers of positive and negative signs in the exploitation (exploited) relationships, else, the 6 pairs of competition relationships and the 9 pairs of mutualism relationships can offset each other for 6 pairs. Based on Eq. (6), Synergism index (S) was 7.05, showing synergism happens at HFETA. $M$ and $S$ reflect the quantitative and qualitative situation of mutual relationships among metabolic components from the holistic view.

\subsubsection{Specific ecological relationships between compartments}

The direct relationships between environment and industrial sectors are $\left(\operatorname{sd}_{12}, \mathrm{sd}_{21}\right)=(-,+),\left(\operatorname{sd}_{13}, \mathrm{sd}_{31}\right)=(-,+),\left(\mathrm{sd}_{14}, \mathrm{sd}_{41}\right)=(+,-)$, $\left(\operatorname{sd}_{15}, \operatorname{sd}_{51}\right)=(-,+),\left(\operatorname{sd}_{16}, \operatorname{sd}_{61}\right)=(+,-),\left(\operatorname{sd}_{17}, \operatorname{sd}_{71}\right)=(+,-)$, indicating that environment is exploited by thermal power plant, automobile manufacturing industry and household appliances industry, while environment exploits equipment manufacturing industry, fast moving consumer goods industry and other industry. The ecological relationship between environment and waste treatment sector is $\left(\mathrm{sd}_{18}\right.$, $\left.\operatorname{sd}_{81}\right)=(-,+)$, signifying environment supports the running of waste treatment sector. Excluding environment, thermal power plant was exploited by the other nodes, as shown as $\left(\mathrm{sd}_{23}, \mathrm{sd}_{32}\right)=(-,+),\left(\mathrm{sd}_{24}\right.$, $\left.\operatorname{sd}_{42}\right)=(-,+),\left(s_{25}, s d_{52}\right)=(-,+),\left(\operatorname{sd}_{26}, s d_{62}\right)=(-,+),\left(s d_{27}\right.$, $\left.\mathrm{sd}_{72}\right)=(-,+),\left(\mathrm{sd}_{28}, \mathrm{sd}_{82}\right)=(-,+)$. The relationships between automobile manufacturing and other industry, and between automobile manufacturing and waste treatment are both being exploited $\left(\left(\mathrm{sd}_{37}\right.\right.$, $\left.\left.\operatorname{sd}_{73}\right)=(-,+),\left(\operatorname{sd}_{38}, \mathrm{sd}_{83}\right)=(-,+)\right)$, while environment and thermal power plant support the development of automobile manufacturing industry. $\left(\mathrm{sd}_{47}, \mathrm{sd}_{74}\right)=(-,+)$, and $\left(\mathrm{sd}_{48}, \mathrm{sd}_{84}\right)=(-,+)$ means equipment manufacturing industry is exploited by other industry and waste treatment sector. $\left(\mathrm{sd}_{57}, \mathrm{sd}_{75}\right)=(+,-)$, and $\left(\mathrm{sd}_{58}, \mathrm{sd}_{85}\right)=(-,+)$ show that household appliances industry exploits other industry, and is exploited by waste treatment sector. $\left(\operatorname{sd}_{67}, s d_{76}\right)=(+,-)$ shows fast moving consumer goods is supported by other industry. Fast moving consumer goods is exploited by waste treatment $\left(\left(\operatorname{sd}_{68}, \mathrm{sd}_{86}\right)=(-\right.$, $+)$ ). Other industry provides resources for waste treatment sector $\left(\left(\mathrm{sd}_{78}, \mathrm{sd}_{87}\right)=(-,+)\right)$.

To survey the ecological relationships in a system only by direct utility is biased, since the indirect utility do have an important impact on the whole network; it is necessary and rational to use integral utility to reveal the ecological relationships in the network. We can scan the change of the relationship among sectors through D to U (Fig. 2). The relationship between environment and waste treatment sector changes from $\left(\mathrm{sd}_{18}, \mathrm{sd}_{81}\right)=(-,+)$ to $\left(\mathrm{su}_{18}, \mathrm{su}_{81}\right)=(+,+)$, indicating a change from exploitation of environment by waste treatment sector to mutualism. The relationship between thermal power plant and equipment manufacturing industry, between thermal power plant and fast moving consumer goods industry change from $\left(\mathrm{sd}_{24}, \mathrm{sd}_{42}\right)=(-,+)$, $\left(\mathrm{sd}_{26}, \mathrm{sd}_{62}\right)=(-,+)$ to $\left(\mathrm{su}_{24}, \mathrm{su}_{42}\right)=(+,+),\left(\mathrm{su}_{26}, \mathrm{su}_{62}\right)=(+,+)$, indicating the relationship between thermal power plant and equipment manufacturing industry, between thermal power plant and fast moving consumer goods industry have become mutualistic relationship. $\left(\mathrm{sd}_{27}, \mathrm{sd}_{72}\right)=(-,+)$ changes to $\left(\mathrm{su}_{27}, \mathrm{su}_{72}\right)=(+,-)$, meaning the relationship between thermal power plant and other industry becomes other industry being exploited by thermal power plant. $\left(\mathrm{sd}_{34}, \mathrm{sd}_{43}\right)=$ $(0,0),\left(\mathrm{sd}_{36}, \mathrm{sd}_{63}\right)=(0,0)$ changes to $\left(\mathrm{su}_{34}, \mathrm{su}_{43}\right)=(+,+),\left(\mathrm{su}_{36}\right.$, $\left.\mathrm{su}_{63}\right)=(+,+)$, reflecting the relationship between automobile manufacturing industry and equipment manufacturing industry, between automobile manufacturing industry and fast moving consumer goods industry change from neutralism to mutualism. $\left(\mathrm{sd}_{35}, \mathrm{sd}_{53}\right)=(0,0)$ changes to $\left(\mathrm{su}_{35}, \mathrm{su}_{53}\right)=(-,-)$, showing the relationship between automobile manufacturing industry and household appliances industry changes from neutralism to competition. The relationship between automobile manufacturing industry and other industry changes from automobile manufacturing industry being exploited by other industry $(-,+)$ to mutualism $(+,+)$. The relationship between equipment manufacturing industry and household appliances industry, between equipment manufacturing industry and fast moving consumer goods industry change from neutralism $(0,0)$ to mutualism $(+,+)$, and from neutralism $(0,0)$ to competition $(-,-)$. The relationship between equipment manufacturing industry and other industry changes from $\left(\mathrm{sd}_{47}\right.$, $\left.\operatorname{sd}_{74}\right)=(-,+)$ to $\left(\mathrm{su}_{47}, \mathrm{su}_{74}\right)=(-,-)$, indicating a change from exploitation of equipment manufacturing industry by other industry to competition. The relationship between household appliances industry and fast moving consumer goods industry changes from neutralism $(0$, $0)$ to mutualism $(+,+) .\left(\mathrm{sd}_{57}, \mathrm{sd}_{75}\right)=(+,-)$ changes to $\left(\mathrm{su}_{57}, \mathrm{su}_{75}\right)$ $=(+,+)$, showing the relationship changes from exploitation to mutualism. The relationship between fast moving consumer goods industry and other industry changes from $\left(\mathrm{sd}_{67}, \mathrm{sd}_{76}\right)=(+,-)$ to $\left(\mathrm{su}_{67}, \mathrm{su}_{76}\right)=(-,-)$, indicating the relationship changes from exploitation to competition.

Three mutualism relationships relates to automobile manufacturing industry: $\left(\mathrm{su}_{43}, \mathrm{su}_{34}\right)=(+,+),\left(\mathrm{su}_{63}, \mathrm{su}_{36}\right)=(+,+)$, and $\left(\mathrm{su}_{73}\right.$, $\left.\mathrm{su}_{37}\right)=(+,+)$, meaning that automobile manufacturing industry has established mutualism relationships with equipment manufacturing, fast moving consumer goods industry, and other industry. Also, household appliances industry has three mutualism relationships with equipment manufacturing, fast moving consumer goods industry and other industry: $\left(\mathrm{su}_{54}, \mathrm{su}_{45}\right)=(+,+),\left(\mathrm{su}_{56}, \mathrm{su}_{65}\right)=(+,+)$, and $\left(\mathrm{su}_{57}\right.$, $\left.\mathrm{su}_{75}\right)=(+,+)$. Thermal power plant supplies heat to equipment manufacturing industry and fast moving consumer goods industry, while these two sectors provide indirect flow to thermal power plant through other nodes, for instance, environment. The remaining mutualism relationship is between environment and waste treatment sector. 

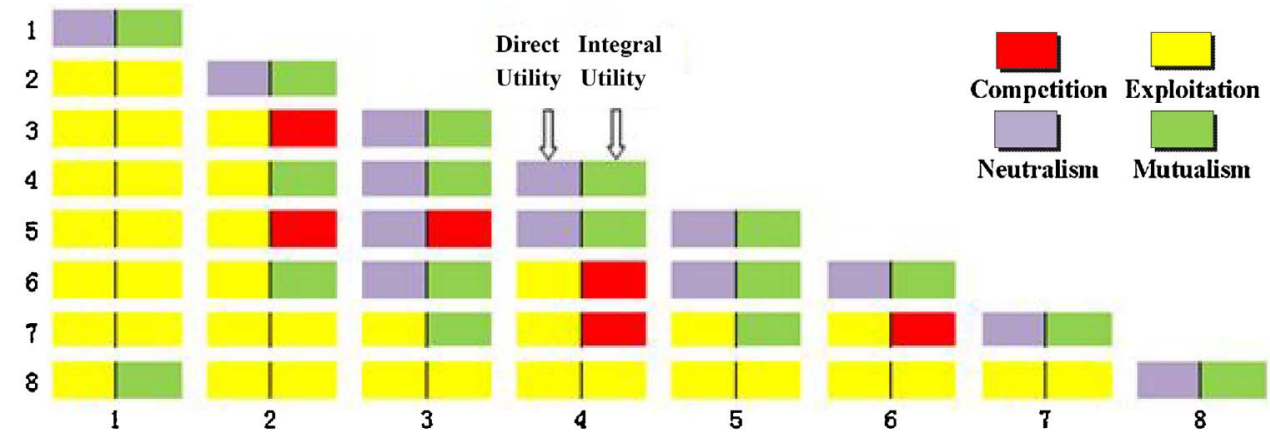

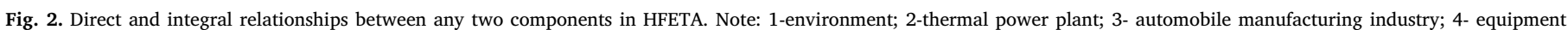
manufacturing industry; 5- household appliances industry; 6- fast moving consumer goods industry; 7- other industry; 8- waste treatment sector.

Direct flow exists between environment and waste treatment sector, but the industrial sectors play a significant role in forming a mutualism relationship between them. These results suggest that quite a part of the mutualism relationships originate from indirect flows among sectors in the network.

Environment and waste treatment sector don't form competition relationship with any component. Among the 6 pairs of competition relationships, three pairs are $\left(\mathrm{su}_{25}, \mathrm{su}_{52}\right)=(-,-),\left(\mathrm{su}_{23}, \mathrm{su}_{32}\right)=(-$, $-)$, and $\left(\mathrm{su}_{35}, \mathrm{su}_{53}\right)=(-,-)$, showing that thermal power plant, automobile manufacturing industry and household appliances industry have formed competition relationships between every pair of them. Waste/byproducts exchange should be strengthened among these components. These three components should take options to improve their eco-efficiency. $\left(\mathrm{su}_{46}, \mathrm{su}_{64}\right)=(-,-),\left(\mathrm{su}_{47}, \mathrm{su}_{74}\right)=(-,-)$, and $\left(\mathrm{su}_{67}, \mathrm{su}_{76}\right)=(-,-)$ indicate that equipment manufacturing industry, fast moving consumer goods industry and other industry have constructed competition relationships between every pair of them.

\subsubsection{Network stability}

Based on Eqs. (6)-(8), NS value equals 0.70 (Table 2), indicating a lower resilience of the network system than its efficiency. Most of the flows contributed to the efficiency rather than the resilience in the metabolic system of HFETA. In other words, HFETA is in the evolutionary phase, and the insufficient resilience might make the study park vulnerable when facing disturbance, for instance, a reduction of resources supply. However the metabolic links among the components at HFETA are in a relatively stable state from a holistic perspective.

System robustness (R), system ascendency (A) and system redundancy $(\theta)$ are calculated according to Eqs. (9)-(12). $R=0.16$ indicates that the system has a certain degree of robustness. Results show that the system capacity is $7.47 \mathrm{E}+21 \mathrm{sej}$, and there are a lot more redundancy $(5.37 \mathrm{E}+21 \mathrm{sej})$ than the ascendency $(2.10 \mathrm{E}+21 \mathrm{sej})$ in the system of HFETA. The park should adjust the flows to turn the system redundancy to ascendency. The redundancy, however, should not be too little. Otherwise, it will affect the network stability. Redundancy reflects the degree to which pathways in a network are duplicated so that the connection between components cannot be cut apart by removing a single intervening link.

Table 2

Network stability indicators at HFETA.

\begin{tabular}{lll}
\hline Indicators & Meaning & Value \\
\hline NS & Network stability & 0.70 \\
R & Robustness & 016 \\
A & Ascendency & $2.10 \mathrm{E}+21$ sej \\
$\theta$ & Redundancy & $5.37 \mathrm{E}+21$ sej \\
C & Capacity & $7.47 \mathrm{E}+21$ sej \\
\hline
\end{tabular}

\section{Discussion}

The industrial parks can be characterized and analyzed by direct and indirect interactions between different system components. In our study the SNA and ENA approach are crucial to disclose the structure and characteristics of the industrial metabolic system in accordance with mutual ecological relationships and network stability. Environment was located in the center of the metabolic network. The resource flows obtained from environment dominated the metabolic magnitude of the park, composing a linear and irreversible supply chain. It suggests that resources are used to support the daily operation of industrial park, where the environment plays a fundamental role. It was the environmental endowment that provided almost all original sources of resources, maintained and controlled other components. Protecting environment is of great importance to maintain this network. A high density (0.5714) in the network shows the dense connections between components in the network. In addition to the environment, other industry plays a significant role in constructing the network. Automobile manufacturing industry, equipment manufacturing industry, household appliances industry, and fast moving consumer goods industry were located in the periphery of the network, we should create more links between these nodes by looking for waste/byproduct exchange and energy cascading opportunities.

The mutual flows among components were used to compute the direct utility intensity matrix (D) and the integral utility intensity matrix (U) for the study area. We can determinate the relationship dynamic and calculate $M$ and S for HFETA based on D and U. The exploitative (exploited) relationships accounted for the majority of the ecological relationships in this system, indicating that components in this system are inclined to exploit others. It is helpful in promoting the exchanges of products, byproducts or waste among components, and also through transmitting the materials between nodes, the system can find positive benefits. The total integral utility of the relationships is positive, so these relationships contribute net positive benefits for the overall system ultimately. There are a few relationships formed by indirect flows via intermediate component between two components which have no direct relationship. For example, equipment manufacturing industry connected with household appliances industry through other industry.

In our study we found that the flows could influence the special ecological relationships between nodes and the overall relationship of the industrial park. We also identified the key nodes and pathways. These can help to promote eco-industrial development by regulating flows, which can be achieved, for example, through connecting nodes by reusing residuals since it can save resources. Creating symbiotic relationships among the nodes would also contribute to achieve ecoindustrial development targets. Regulating the flows including cutting the raw material flows and replacing supply chains with residual reuse flows such as reusing straw from environment as biomass fuel to other 
industry could help to construct symbiotic relationships.

Network stability analysis was introduced into the ecological network analysis framework providing insights into the metabolic system. The stability analysis also depicts a perspective of the model based on information theory, which indicates that HFETA is in its evolutionary stage with higher efficiency and lower resilience. The system ascendency and redundancy, complementary parts of system capacity, reflect the conflict between excessive redundancy and deficient ascendency. Therefore it is crucial to improve the network structure through resources flow optimization. The robustness value means the overall network system has a certain amount of robustness. The optimal level of robustness for a system depends on the environment, development stage, stresses levels, industry features and the mechanism forming the network. The challenge here is to find the optimal level of robustness for this kind of system. One way of attaining this is simulating the natural world's patterns and strategies as a normative paradigm.

\section{Conclusion}

In our study, we built a network for the industrial metabolism and analyzed the industrial metabolic system of HFETA. With emergy method quantifying the flows between diverse components, SNA and ENA were used to study the characteristics, the overall performance of the metabolic network at HFETA, and ecological relationships. Compared with the traditional metabolic analytical approaches, more detailed insights into the industrial metabolism were revealed by SNA and ENA. The results reflect the behaviors and potential linkage of system components and reveal the structure, function, and mutualism condition of the industrial metabolic system in the study park. From sign (D) to sign (U), the ecological relationships changed since indirect flows occurred between components. HFETA's case shows that the indirect pathways connecting flows play important roles in an industrial metabolic system. The development of most of industrial sectors depends on the environment and thermal power plant. Automobile manufacturing industry has established mutualism relationships with equipment manufacturing, fast moving consumer goods industry, and other industry. Thermal power plant, automobile manufacturing industry and household appliances industry have formed competition relationships between every pair of them. The park should regulate flows to adjust the relationships for improving the system's sustainability. Mutualism index $(M=1.56)$ and Synergism index $(S=7.05)$ indicate that the industrial metabolic system presents an overall degree of synergism and mutualism. NS $=0.70$ means that the resilience of the network system is relatively lower than the efficiency, reflecting the system is in evolutionary phase; most flows are used to contribute to the system efficiency. Robustness of the system (R) is 0.16 , signifying that the system has a certain amount of robustness. This paper could help to provide a deep insight into the industrial park metabolic structure; else, it provides a basis for optimizing the whole industrial process in industrial park by adjusting the flows.

Nevertheless, there is still much room to explore industrial metabolic mechanism in industrial parks. SNA and ENA are static analyses which are deficient to perform a metabolic dynamic simulation. On the other hand, more complex flows between finer-grained compartments should be further analyzed in detail to obtain a more comprehensive understanding on the industrial metabolism of an industrial park in future study.

\section{Acknowledgements}

We are grateful of reviewers' of inputs and assistances in revising the manuscript. This work is supported by the National Natural Science Foundation of China (No. 71373248). This study was also supported by State Key Laboratory of Environmental Criteria and Risk Assessment, Chinese Research Academy of Environmental Sciences.

\section{Appendix A}

\section{Appendix A. Supplementary data}

Supplementary data associated with this article can be found, in the online version, at http://dx.doi.org/10.1016/j.resconrec.2017.05.009.

Table A1

Emergy flows accounting between sectors in the industrial park.

\begin{tabular}{|c|c|c|c|c|c|c|c|c|c|}
\hline \multirow[t]{2}{*}{ Flow(sej) } & & \multicolumn{8}{|l|}{ from } \\
\hline & & 1 & 2 & 3 & 4 & 5 & 6 & 7 & 8 \\
\hline \multirow[t]{15}{*}{ to } & 1 & & $1.46 \mathrm{E}$ & $2.80 \mathrm{E}$ & $5.15 \mathrm{E}$ & $1.18 \mathrm{E}$ & $2.68 \mathrm{E}$ & $7.42 \mathrm{E}$ & $1.28 \mathrm{E}$ \\
\hline & & & +20 & +20 & +20 & +21 & +20 & +20 & +16 \\
\hline & 2 & $\begin{array}{l}1.08 \mathrm{E} \\
+21\end{array}$ & & & & & & & \\
\hline & 3 & $5.52 \mathrm{E}$ & $3.74 \mathrm{E}$ & & & & & & \\
\hline & & +20 & +18 & & & & & & \\
\hline & 4 & $4.43 \mathrm{E}$ & $1.18 \mathrm{E}$ & & & & $1.54 \mathrm{E}$ & & \\
\hline & & +20 & +19 & & & & +12 & & \\
\hline & 5 & $1.32 \mathrm{E}$ & $3.16 \mathrm{E}$ & & & & & $1.14 \mathrm{E}$ & \\
\hline & & +21 & +19 & & & & & +18 & \\
\hline & 6 & $1.75 \mathrm{E}$ & $1.80 \mathrm{E}$ & & & & & $8.27 \mathrm{E}$ & \\
\hline & & +20 & +19 & & & & & +18 & \\
\hline & 7 & $4.01 \mathrm{E}$ & $4.08 \mathrm{E}$ & $2.03 \mathrm{E}$ & $1.64 \mathrm{E}$ & $1.09 \mathrm{E}$ & $2.03 \mathrm{E}$ & & $1.45 \mathrm{E}$ \\
\hline & & +20 & +19 & +17 & +17 & +17 & +17 & & +18 \\
\hline & 8 & $9.22 \mathrm{E}$ & $7.05 \mathrm{E}$ & $2.92 \mathrm{E}$ & $4.83 \mathrm{E}$ & $2.26 \mathrm{E}$ & $1.85 \mathrm{E}$ & $5.89 \mathrm{E}$ & \\
\hline & & +17 & +18 & +18 & +18 & +18 & +18 & +18 & \\
\hline
\end{tabular}




\section{References}

Ahuja, R.K., Magnanti, T.L., Orlin, J.B., 1988. Network Flows. Alfred P Sloan School of Management, Cambridge MA.

Andersen, F.M., Larsen, H., Skovgaard, M., Moll, S., Isoard, S., 2007. A European model for waste and material flows. Resour. Conserv. Recycl. 49 (4), 421-435.

Baird, D., Asmus, H., Asmus, R., 2008. Nutrient dynamics in the sylt-Rømø bight ecosystem, German Wadden Sea: an ecological network analysis approach. Estuarine Coast. Shelf Sci. 80 (3), 339-356.

Balakrishnan, V.K., 1997. Graph Theory, 1st ed. McGraw-Hill, Newyork.

Bao, X., 2013. Exploring a Road to Ecological Transformation for Industrial Parks. Economic Daily The Economic Daily Press Group, Beijing, China.

Borgatti, S.P., 2002. NetDraw: graph visualization software. harvard: analytic technologies. In: Borgatti, S.P., Everett, M.G., Freeman, L.C. (Eds.), Ucinet for Windows: Software for Social Network Analysis. Analytic Technologies Harvard, pp. 2002.

Borrett, S.R., Patten, B.C., 2003. Structure of pathways in ecological networks: relationships between length and number. Ecol. Model. 170 (2-3), 173-184.

Brown, M.T., Bardi, E., 2001. Folio\# 3: Emergy of Ecosystems. Handbook of Emergy Evaluation: a Compendium of Data for Emergy Computation Issued in a Series of Folios. Center for Environmental Policy, University of Florida, Gainesville, FL, USA.

CADZ (China Association of Development Zone), 2014. China Development Zone Statistics. China finance and Economics Press, Beijing.

Chinowsky, P., Taylor, J.E., 2012. Networks in engineering: an emerging approach to project organization studies. Eng. Proj. Organ. J. 2 (1-2), 15-26.

Erkus-Ozturk, H., Eraydin, A., 2010. Environmental governance for sustainable tourism development: collaborative networks and organisation building in the Antalya tourism region. Tour. Manage. 31, 113-124.

Fath, B.D., Borrett, S.R., 2006. A MATLAB function for network environ analysis. Environ. Modell. Soft. 21 (3), 375-405.

Fath, B.D., Patten, B.C., 1998. Network synergism: emergence of positive relations in ecological systems. Ecol. Model. 107, 127-143.

Fath, B.D., Patten, B.C., 1999a. Review of the foundations of network environ analysis. Ecosystems 2 (2), 167-179.

Fath, B.D., Patten, B.C., 1999b. Review of the foundations of network environ analysis. Ecosystems 2 (2), 167-179.

Fath, B.D., 2007. Network mutualism: positive community-level relations in ecosystems. Ecol. Model. 208 (1), 56-67.

Fath, B.D., 2012. Analyzing ecological systems using network analysis. Ecol. Questions 16 (1), 77.

Finn, J.T., 1976. Measures of ecosystem structure and function derived from analysis of flows. J. Theor. Biol. 56, 363-380.

Freeman, L.C., 1997. Centrality in social networks: conceptual clarification. Soc Net. 1, 215-239.

Furht, B., 2010. Handbook of Social Network Technologies and Applications. Springer: Florida Atlantic Universitypp. 3-14.

Ghafouri, H.B., Mohammadhassanzadeh, H., Shokraneh, F., Vakilian, M., Farahmand, S., 2014. Social network analysis of Iranian researchers on emergency medicine: a sociogram analysis. Eme Med. J. 31, 619-624.

Håkansson, H., 1997. Organization Networks. The Handbook of Organizational Behaviour. Thomson, London, pp. 232-240.

Hanneman, R.A., Riddle, M., 2005. Introduction to Social Network Methods.

Huisman, M., Van Duijn, M.A.J., 2005. Software for social network analysis. Models Methods Soc. Network Anal. 270, e316.

Jørgensen, S.E., Fath, B., 2006. Examination of ecological networks. Ecol. Model. 196 (3-4), 283-288.

Kim, J., Perez, C., 2015. Co-authorship network analysis in industrial ecology research community. J. Ind. Ecol. 19 (2), 222-235.

Liu, Z., Adams, M., Cote, R.P., Geng, Y., Li, Y., 2016. Comparative study on the pathways of industrial parks towards sustainable development between China and Canada. Resour. Conserv. Recycl. http://dx.doi.org/10.1016/j.resconrec.2016.06.012.

Love, A., Andrew, D.P.S., 2012. The intersection of sport management and sociology of sport research: a social network perspective. Sport Manage. Rev. 15, 244-256.

Low, B.K.H., 1997. Managing business relationships and positions in industrial networks. Ind. Mark. Manage. 26 (2), 189-202.

Molles, M.C., Cahill, J.F., 1999. Ecology: Concepts and Applications. WCB/McGraw-Hill,
Dubuque, IA.

Nandy, B., Sharma, G., Garg, S., Kumari, S., George, T., Sunanda, Y., Sinha, B., 2015. Recovery of consumer waste in India-A mass flow analysis for paper, plastic and glass and the contribution of households and the informal sector. Resour. Conserv. Recycl. $101,167-181$.

Nasini, S., Castro, J., Fonseca, P., 2015. A mathematical programming approach for different scenarios of bilateral bartering. SORT-Stat. Oper. Res. Trans. 39 (1), 85-108.

Odum, H.T., Brown, M.T., Brandt-Williams, S.L., 2000. Folio\# 1: Introduction and Global Budget. Handbook of Emergy Evaluation: A Compendium of Data for Emergy Computation Issued in a Series of Folios. Center for Environmental Policy, Univ. of Florida, Gainesville.

Odum, H.T., 1988. Self-organization, transformity and information. Science 242 (4882), 1132-1139.

Odum, H.T., 1996. Environmental Accounting: Emergy and Environmental Decision Making. John Wiley and Sons, New York.

Patten, B.C., Higashi, M., 1995. First passage flows in ecological networks: measurement by input-output flow analysis. Ecol. Model. 79 (1-4), 67-74.

Patterson, P.D., Pfeiffer, A.J., Weaver, M.D., Krackhardt, D., Arnold, R.M., Yealy, D.M., Lave, J.R., 2013. Network analysis of team communication in a busy emergency department. BMC Health Serv. Res. 13, 109.

Provan, K.G., Milward, H.B., 1995. A preliminary theory of inter-organizational network effectiveness: a comparative study of four community mental health systems. Admin. Sci. Q. 40, 1-33.

Quatman, C., Chelladurai, P., 2008. The social construction of knowledge in the field of sport management: a social network perspective. J. Sport. Manage. 22, 651-676.

Sapountzi, A., Psannis, K.E., 2016. Social networking data analysis tools \& challenges. Future Gener. Comput. Syst. https://doi.org/10.1016/j.future.2016.10.019.

Schaubroeck, T., Staelens, J., Verheyen, K., Muys, B., Dewulf, J., 2012. Improved ecological network analysis for environmental sustainability assessment; a case study on a forest ecosystem. Ecol. Model. 247, 144-156.

Schiller, F., Penn, A.S., Basson, L., 2014. Analyzing networks in industrial ecology?a review of Social-Material Network Analyses. J. Clean. Prod. 76, 1-11.

Scott, N., Baggio, R., Cooper, C., 2011. Network analysis methods for modeling tourism inter-organizational systems. In: Woodside, A.G. (Ed.), Tourism Sensemaking: Strategies to Give Meaning to Experience. Advances in Culture, Tourism and Hospitality Research. Emerald Group Publishing Limited, pp. 177-221.

Scott, J., 2012. Social Network Analysis. Sage publications.

Shannon, C.E., Weaver, W., 1948. A mathematical theory of communication. Bell Syst. Tech. J. 27, 379-423 and 623-656.

Ulanowicz, R.E., Goerner, S.J., Lietaer, B., Gomez, R., 2009. Quantifying sustainability: resilience, efficiency and the return of information theory. Ecol. Complex. 6 (1), 27-36.

Ulanowicz, R.E., 2001. Information theory in ecology. Comput. Chem. 25 (4), 393-399.

Ulanowicz, R.E., 2004. Quantitative methods for ecological network analysi. Comp. Biol. Chem. 28 (5-6), 321-339.

Ulanowicz, R.E., 2011. Quantitative Methods for Ecological Network Analysis and Its Application to Coastal Ecosystems Treatise on Estuarine and Coastal Science. Academic Press, Waltham, pp. 35-57.

Analysis and Modeling of Complex Data in Behavioral and Social Sciences. In: Vicari, D., Okada, A., Ragozini, G., Weihs, C. (Eds.), Springer International Publishing.

Wasserman, S., Faust, K., 1994. Social Network Analysis: Methods and Applications. Cambridge University Press.

Yang, Z., Mao, X., Zhao, X., Chen, B., 2012. Ecological network analysis on global virtual water trade. Environ. Sci. Technol. 46 (3), 1796-1803.

Yune, J.H., Tian, J., Liu, W., Chen, L., Descamps-Large, C., 2016. Greening Chinese chemical industrial park by implementing industrial ecology strategies: a case study. Resour. Conserv. Recycl. 112, 54-64.

Zhang, L., Wang, H., 2006. Planning an ecological network of Xiamen Island (China) using landscape metrics and network analysis. Landscape Urban Plan. 78 (4), $449-456$.

Zhang, Y., Zheng, H., Chen, B., Yang, N., 2013. Social network analysis and network connectedness analysis for industrial symbiotic systems: model development and case study. Front. Earth Sci. 7 (2), 169-181.

Zhang, Y., Zheng, H., Shi, H., Yu, X., Liu, G., Su, M., Li, Y., Chai, Y., 2016. Network analysis of eight industrial symbiosis systems. Front. Earth Sci. 10 (2), 352-365. 